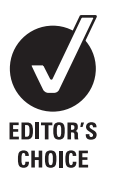

${ }^{1}$ Consell Català de l'Esport, Generalitat de Catalunya, Barcelona, Spain; ${ }^{2}$ Fremap Cantabria, Real Sporting de Gijón, Gijón, Spain; ${ }^{3}$ Physical Activity and Sports Professional Medicine School, University of Barcelona, Barcelona, Spain;

${ }^{4}$ Unitat Medicina de l'esport, Fundació Hospital Comarcal Sant Antoni Abad, Vilanova i la Geltrú, Spain; ${ }^{5}$ Drim Medical,

Barcelona, Spain; ${ }^{6}$ Hospital de Cabueñes, Giión, Spain:

${ }^{7}$ Aspetar Hospital, National Sports Medicine Program, Doha, Qatar

Correspondence to: Dr R Balius, Consell Català de l'esport, Sant Mateu s/n St,

Esplugues del Llobregat, Barcelona 08950, Spain; rbalius@gencat.cat; 23684rbm@comb.es

Accepted 19 November 2008 Published Online First

13 March 2009

\title{
Central aponeurosis tears of the rectus femoris: practical sonographic prognosis
}

\author{
R Balius, ${ }^{1}$ A Maestro, ${ }^{2}$ C Pedret, ${ }^{3,4}$ A Estruch, ${ }^{1}$ J Mota, ${ }^{5}$ L Rodríguez, ${ }^{6}$ P García, ${ }^{6}$ \\ E Mauri $^{7}$
}

\begin{abstract}
Objective: This study is a statistical analysis to establish whether a correlation exists between the level and degree of rectus femoris (RF) central tendon injury and the amount of time that an athlete is unable to participate subsequently, referred to as "sports participation absence" (SPA).

Design: Causal-comparative study.
\end{abstract}

Patients: 35 players from two high-level Spanish soccer teams with an injury to the central tendon of the RF based on clinical and ultrasound criteria.

Main Outcome Measure: Ultrasound examination was performed with an 8-2 $\mathrm{MHz}$ linear multifrequency transducer. All studies included both longitudinal and transverse RF sections.

Results: At the proximal level the SPA time is 45.1 days when the injury length is $4.0 \mathrm{~cm}$. This value increases by 5.3 days with each $1 \mathrm{~cm}$ increase in the length of injury. In the case of distal level injury, SPA time is 32.9 days when the injury length is $3.9 \mathrm{~cm}$. This value increases by 3.4 days with each $1 \mathrm{~cm}$ increase. In the total representative sample, SPA time when the injury length is $4.2 \mathrm{~cm}$ corresponds to 39.1 days. This value increases by 4.2 days per length unit.

Conclusions: RF central tendon injury at the proximal level is associated with a greater SPA time than at the distal level. Patients with a grade II injury have an SPA time longer than those with a grade I injury whether the injury is located proximal or distal.

The rectus femoris (RF) muscle is particularly vulnerable to injury because of the following characteristics: it spans two joints; the majority of its fibres are type II fast twitch; it performs eccentric-specific work during sporting activities. ${ }^{1}$

This study is a statistical analysis to establish whether a correlation exists between the level and degree of RF central tendon injury and the amount of time that an athlete is unable to participate, subsequently referred to as "sports participation absence" (SPA).

Data were collected over a 4-year period (20025) from high-level soccer players in different categories.

\section{PATIENTS AND METHODS}

We recruited 35 players from two high-level Spanish soccer teams. We chose ultrasound as the main exploration method because of its accessibility in our clinical practice, its lower cost and its comparability to magnetic resonance imaging (MRI). The clinical diagnosis was based on acute pain in the anterior thigh during physical soccer activity according to the Union of European Football Associations criteria. ${ }^{23}$

No pain due to delayed onset muscle soreness or direct trauma was included in the study. ${ }^{4}$

Variables such as weight (kilograms), age (years), height (centimetres) and days delayed to the first medical consultation were registered along with dominance of the lower extremity involved. We have also excluded those players with previous RF injury or with any other lower extremity injury that occurred 5 months before the present injury.

\section{Ultrasound examination}

Ultrasound examination was performed using a Toshiba PowerVision ultrasound with an 8$12 \mathrm{MHz}$ linear multifrequency transducer. All studies included both longitudinal and transverse RF sections. ${ }^{5}$

Ultrasound examination was performed by a sports physician in one club and a radiologist in the other. Both sonologists are recognised experts in ultrasound (in Spain and some other European countries the muscular ultrasound examination is commonly performed by sports physicians). ${ }^{6}$ The echographic criteria were agreed before the start of the study.

Injuries to the central tendon topography were divided into two groups: proximal and distal. We define a proximal lesion as one that is located above the intersection created between the lateral edge of the sartorius muscle and medial edge of the RF (fig 1). Distal lesions are those below this line (fig 2).

We chose to evaluate the RF injury with the Peetrons classification as a result of its wide acceptance and ease of application. Measurement of the cross-sectional area (CSA) of the injury along with the injury percentage (CSA\%) in the axial plane has been validated with MRI. The CSA has only been validated with ultrasound in healthy muscle. ${ }^{7}$ CSA\% in injured muscle has not yet been validated with ultrasound as a result of its technical difficulty.

Peetrons classification (2002) for assessing the degree of disruption by ultrasound was utilised with the following grading system: grade 0 represents a negative ultrasound, negative with positive clinical findings; grade I lesions represent an ill-defined hyper or hypoechoic area without objective fibrillar discontinuity or inflammation of the fascia; grade II lesions represent a partial fibrillar discontinuity; grade III lesions represent complete discontinuity of the fibrillar structure. This kind of injury is referred to us as a "bull's eye lesion" in MRI in most of the cases. ${ }^{8-10}$ Our 

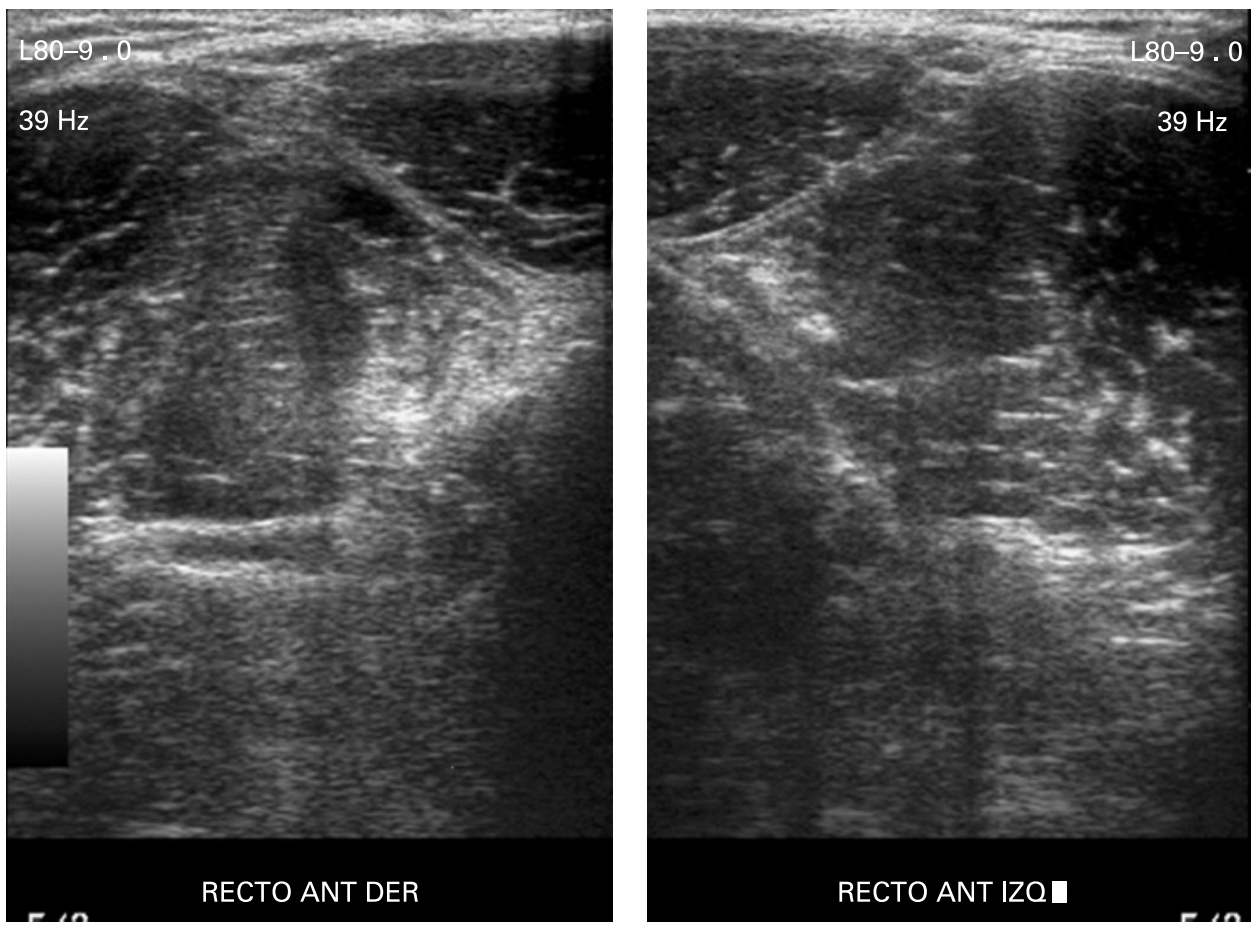

Figure 1 Proximal axial bilateral image of the rectus femoris central tendon. A minimum fluid collection can be seen that causes the central tendon to disappear into the right one (arrowhead). The section of the sartorius can also be seen.

classification only includes injuries graded I, II and III omitting grade $0 .{ }^{11}$

The length of the injury was also recorded by placing a mark on the skin overlying the most distal transverse section of the injury. The probe was then moved proximally until the first appearance of normal tissue. A second mark was placed and the distance between the two marks was measured. ${ }^{12}$

\section{Rehabilitation protocol}

Despite the fact that there is not a universally accepted rehabilitation protocol, ${ }^{9}$ the two clubs used the same programme. It consisted initially of absolute rest for the first week with application of ice, compression and non-steroidal antiinflammatory medication. After a week, a four-stage active recovery was initiated ranging from light running to hard kick
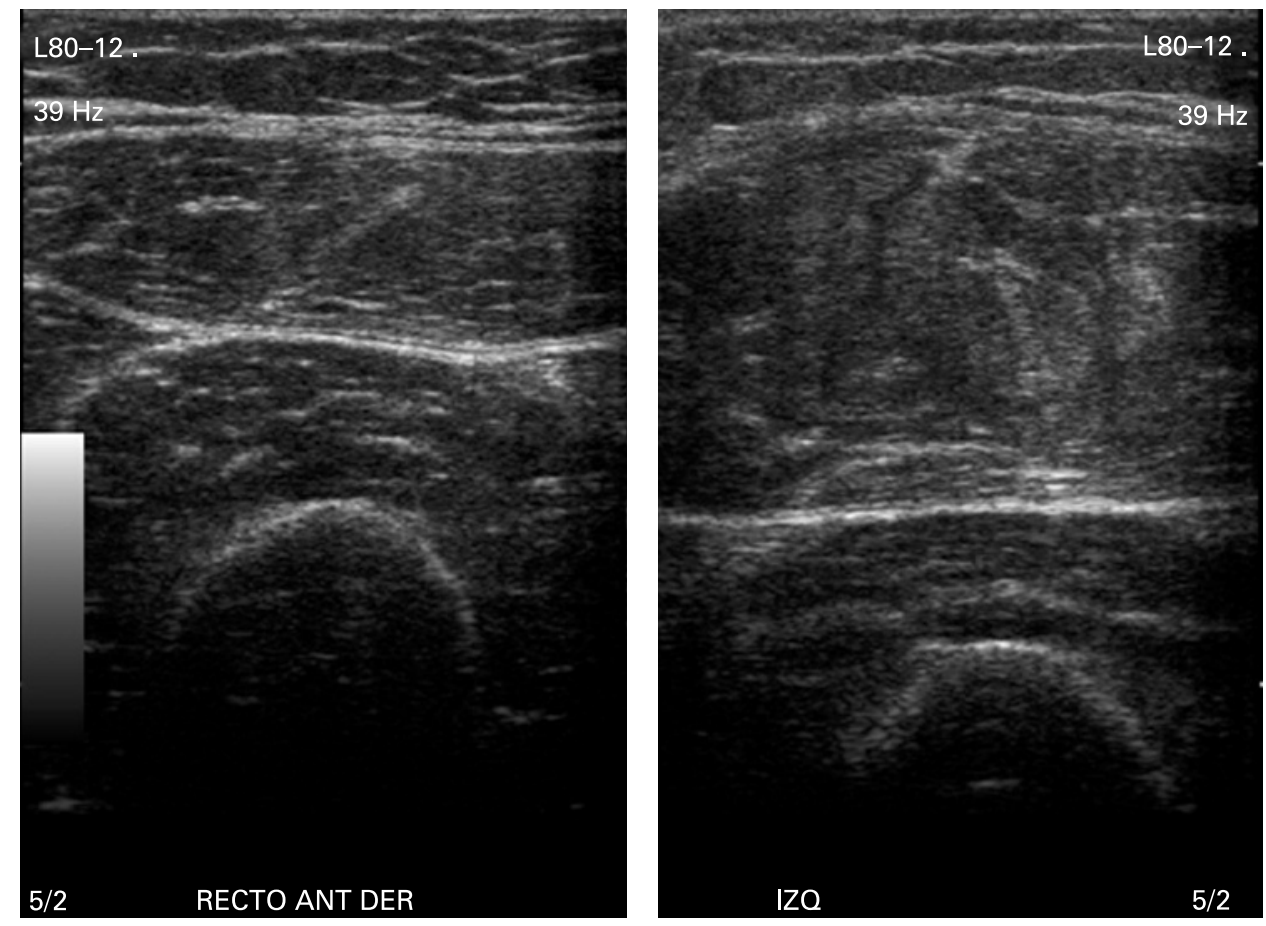

Figure 2 Distal axial bilateral image of the rectus femoris central tendon. The image demonstrates an area of mixed echogenecity surrounding an irregular central tendon in the left one. The muscle is slightly swollen. 
and explosive sprint. To pass from one stage to another the athlete must be absolutely free of pain. ${ }^{9}$

Once again the SPA time was defined as the days taken from the injury until the player returns to full training with the team..$^{2}{ }^{13}$ A player is totally rehabilitated when the medical team considers that he is suitable to re-start soccer activity fully. ${ }^{2}{ }^{13} 14$ We did not use any specific functional or metabolic test for the purpose of evaluating recovery as none of the current testing has been shown to be statistically valid as suggested by Cross and colleagues. ${ }^{9} 1516$

\section{Statistical analysis}

\section{Treatment of study variables}

The "level" variable was treated as categorical: proximal and distal.

Weight, age, height and days delayed to first consultation variables were treated as continuous variables; the dominant leg was treated as categorical. The "SPA" variable, in days, was treated as continuous and categorical (0-30 days, 31-45 days and $>45$ days)

The "length" variable of the lesion was treated as a continuous variable, in centimetres.

The categorical variable grades I (minor), II (moderately severe) and III (severe) have been reduced to two categories (I, minor; and II, moderately severe) because only one patient was classified as a grade III. This change avoids comparisons between grades without statistical power.

Initially, a description of the representative sample was developed through absolute and relative frequencies and measures of central tendency and dispersion. To check the uniformity of the representative sample the KolmogorovSmirnov test and the test of homogeneity of variances from the Levene test were applied.

Comparisons of averages were carried out by $t$ test for comparison of two independent representative samples.

The specific analysis of the SPA time stratified by the level of injury was studied for the correlation between variables with the Pearson correlation. We also calculated a linear regression model taking as the dependent variable SPA time and as the explanatory variable the injury length that was centred on their average to facilitate the model interpretation. This was repeated for the pattern for each level of injury and in the total representative sample.

The type I error was fixed at 5\% (95\% CI). Statistical software SPSS version 13 was used.

\section{RESULTS}

\section{Descriptive variables}

We recruited 35 patients. In 18 (51.4\%) the level of injury was proximal and in 17 (48.6\%) distal (table 1).

Table 1 Patient characteristics and cases description

\begin{tabular}{|c|c|c|c|c|c|c|c|c|c|c|}
\hline & Age (years) & Weight $(\mathrm{kg})$ & Height $(\mathrm{cm})$ & Tight & Dominant & Delayed days & Level & Grade & Lenght & SPA (days) \\
\hline 1 & 25 & 70 & 175 & $D$ & $D$ & 0 & Distal & 1 & 3 & 21 \\
\hline 2 & 16 & 70 & 180 & $D$ & D & 3 & Distal & I & 3 & 30 \\
\hline 3 & 26 & 73 & 180 & I & ND & 1.5 & Proximal & II & 5 & 60 \\
\hline 4 & 40 & 70 & 165 & $D$ & $D$ & 2 & Distal & II & 5 & 30 \\
\hline 5 & 20 & 78 & 180 & $D$ & $D$ & 2 & Proximal & II & 4 & 42 \\
\hline 6 & 28 & 76 & 176 & $D$ & $D$ & 2 & Proximal & II & 7 & 60 \\
\hline 7 & 18 & 67 & 170 & $D$ & $D$ & 1 & Distal & I & 2 & 21 \\
\hline 8 & 22 & 68 & 174 & 1 & ND & 2 & Proximal & II & 3 & 42 \\
\hline 9 & 16 & 68 & 174 & $D$ & $D$ & 4 & Distal & ॥ & 4 & 60 \\
\hline 10 & 16 & 71 & 174 & $D$ & $D$ & 4 & Distal & I & 2 & 30 \\
\hline 11 & 26 & 78 & 178 & $D$ & $D$ & 2 & Distal & I & 5 & 40 \\
\hline 12 & 20 & 65 & 166 & $D$ & $D$ & 2 & Proximal & ॥ & 4 & 42 \\
\hline 13 & 24 & 67 & 173 & I & $D$ & 1 & Proximal & I & 1 & 28 \\
\hline 14 & 26 & 79 & 185 & $D$ & D & 4 & Proximal & ॥ & 8 & 75 \\
\hline 15 & 22 & 75 & 168 & $D$ & D & 3 & Proximal & I & 5 & 45 \\
\hline 16 & 25 & 79 & 184 & $D$ & $D$ & 3 & Distal & 1 & 1 & 15 \\
\hline 17 & 29 & 77 & 176 & $D$ & $D$ & 1 & Proximal & II & 4 & 42 \\
\hline 18 & 25 & 78 & 178 & I & ND & 1 & Proximal & II & 4 & 35 \\
\hline 19 & 28 & 78 & 182 & $D$ & $\mathrm{D}$ & 1 & Proximal & I & 1 & 28 \\
\hline 20 & 27 & 72 & 170 & $D$ & $D$ & 0 & Proximal & I & 1 & 28 \\
\hline 21 & 15 & 66 & 175 & $D$ & $D$ & 4 & Proximal & II & 4 & 60 \\
\hline 22 & 22 & 75 & 180 & $D$ & $D$ & 3 & Distal & I & 3 & 30 \\
\hline 23 & 28 & 81 & 185 & 1 & $D$ & 3 & Distal & 1 & 4 & 21 \\
\hline 24 & 28 & 70 & 175 & I & ND & 3 & Distal & II & 5 & 30 \\
\hline 25 & 26 & 71 & 172 & $D$ & $D$ & 0 & Proximal & ॥ & 3 & 24 \\
\hline 26 & 41 & 80 & 182 & I & ND & 0 & Distal & ॥ & 8 & 45 \\
\hline 27 & 24 & 77 & 184 & $D$ & ND & 0 & Proximal & II & 5 & 42 \\
\hline 28 & 15 & 67 & 170 & $D$ & D & 3 & Distal & ॥ & 2 & 30 \\
\hline 29 & 19 & 73 & 180 & $D$ & ND & 3 & Distal & I & 2 & 21 \\
\hline 30 & 25 & 72 & 175 & $D$ & D & 0 & Proximal & ॥ & 4 & 56 \\
\hline 31 & 19 & 75 & 180 & $D$ & $D$ & 1 & Distal & III & 10 & 45 \\
\hline 32 & 23 & 74 & 180 & $D$ & $D$ & 0 & Proximal & II & 2 & 42 \\
\hline 33 & 27 & 82 & 180 & I & $D$ & 3 & Distal & II & 7 & 60 \\
\hline 34 & 24 & 75 & 174 & $D$ & $\mathrm{D}$ & 3 & Distal & I & 1 & 30 \\
\hline 35 & 30 & 78 & 173 & $D$ & $\mathrm{D}$ & 4 & Proximal & II & 8 & 60 \\
\hline
\end{tabular}


Table 2 Injury length

\begin{tabular}{cccc}
\hline & \multicolumn{2}{l}{ Level } & \\
\cline { 2 - 3 } Length $(\mathbf{c m})$ & $\begin{array}{l}\text { Proximal } \\
\mathbf{n}(\%)\end{array}$ & $\begin{array}{l}\text { Distal } \\
\mathbf{n}(\%)\end{array}$ & $\begin{array}{l}\text { Total } \\
\mathbf{n}(\%)\end{array}$ \\
\hline$<2$ & $3(16.7)$ & $2(11.8)$ & $5(14.3)$ \\
$2-6$ & $12(66.6)$ & $12(70.6)$ & $24(68.6)$ \\
$>6$ & $3(16.7)$ & $3(17.6)$ & $6(17.1)$ \\
Total & $18(100.0)$ & $17(100.0)$ & $35(100.0)$ \\
\hline
\end{tabular}

Percentages calculated on the whole number of patients in each level.

The sample was homogeneous in weight, age, height, delay in consultation and dominant leg regard to the SPA $(p>0.05)$

In 13 cases there existed a previous injury in another location and in three cases in the same RF, all had occurred at least 5 months before.

To pass from one stage to another the athlete must be absolutely free of pain. During the rehabilitation protocol no recurrent muscle strain injury was recorded. In some cases pain prevented progress from one stage to another.

We found 29 cases of peripheral RF muscle strains that were not included in the study sample. Their SPA time was 15.31 days (5-29). We also found two vastus intermediate muscle strains (SPA 9.5).

Fourteen cases of thigh pain without echographic translation were also discarded (Peetrons grade 0 ). Their SPA time was 6.5 days (3-12).

Grade I injuries were located mainly in the distal central tendon (10 cases) and grade II were located proximal (14 cases). Only one grade III lesion was noted, with both in the distal central tendon area.

The injury length was very similar between the proximal septal (4.4 cm, SD 2.4) and distal septal level $(4.5 \mathrm{~cm}, \mathrm{SD} 2.9$; table 2).

Depending on the septal level affected, the injury grade and the SPA time, we found a fairly uniform distribution, with a significant percentage of cases resolving before one month and a similar percentage between one month and one month and a half after being diagnosed (table 3 ).

\section{SPA time comparison}

Comparisons were made between SPA time and injury level (table 4), between SPA time and the grade of the injury (table 5), between SPA time and the levels depending on the grade (table 6) and between SPA time and the grade of injury depending on the level (table 7). Finally, injury length depending on the level (proximal/distal) was compared with SPA time (table 8).
Table 4 SPA time between levels

\begin{tabular}{llll}
\hline Level & Proximal (SD) & Distal (SD) & p Value* (95\% CI) \\
\hline $45.1(14.1)$ & $32.9(13.1)$ & $0.013(2.8$ to 21.6)
\end{tabular}

Average (SD). * Independent samples t test. $95 \% \mathrm{Cl}$, confidence interval of the difference between averages. Comparison of sports participation absence (SPA) time between levels. There is a statistically significant difference in SPA time between the two levels $(p=0.013)$, the positive time difference is what tells us that the SPA time of the proximal level is significantly higher than the SPA time in the distal level.

Table 5 Comparison between SPA time and injury grades

\begin{tabular}{llll}
\hline Grade & I (SD) & II (SD) & p Value* $(95 \%$ CI) \\
\hline $27.7(7.9)$ & $46.8(13.4)$ & $<0.001(-27.1$ to -10.9$)$
\end{tabular}

Average (SD). * Independent samples t test. 95\% Cl, confidence interval of the difference between averages. Grade I, mild injury; grade II, less severe injury. SPA, sports participation absence.

Validating SPA time depending on the length and level of injury, we can see that in all cases, a greater length of injury is associated with more SPA time (table 9).

The linear regression model taking as the dependent variable the SPA time and as the explanatory variable the injury length is described in table 10. At the proximal level the SPA time is 45.1 days when the injury length is $4.0 \mathrm{~cm}$. This value increases by 5.3 days with each $1 \mathrm{~cm}$ increase in the length of injury. In the case of distal level injury, SPA time is 32.9 days when the injury length is $3.9 \mathrm{~cm}$. This value increases by 3.4 days with each $1 \mathrm{~cm}$ increase. In the total representative sample, SPA time when the injury length is $4.2 \mathrm{~cm}$ corresponds to 39.1 days. This value increases by 4.2 days per length unit. The adjusted value of $\mathrm{R}^{2}$ is less than 0.5 .

\section{DISCUSSION}

The RF has a complex origin with a characteristic structure that has been evaluated by imaging methods (MRI, ultrasound) and in cadaveric studies.

Hasselmann et $a l^{17}$ have explained the anatomical differences between two insertions: the anterior and/or superficial (direct) at the proximal level and another deeper (indirect) insertion.

The direct one has its origin at the anterior inferior iliac spine. The indirect tendon originates at the upper edge of the acetabulum and runs parallel to the direct tendon. ${ }^{18}$ The indirect tendon is situated in the medial part of the thigh proximally and is cordlike. It travels laterally to finish in the distal part of the muscle with the appearance of a band.

The direct fibres run from the aponeurotic superficial expansion to the posterior RF fascia. Therefore, its structure is unipennate. The central tendon fibres run medial, lateral and

Table 3 Patients distribution depending on the level, degree and SPA time

\begin{tabular}{|c|c|c|c|c|c|}
\hline \multirow[b]{2}{*}{ Diagnostic level } & \multirow[b]{2}{*}{ Grade } & \multicolumn{3}{|c|}{ SPA time (days) } & \multirow[b]{2}{*}{ Total } \\
\hline & & $\begin{array}{l}0-30 \\
\text { n (\%) }\end{array}$ & $\begin{array}{l}\text { 31-45 } \\
\text { n (\%) }\end{array}$ & $\begin{array}{l}>45 \\
n(\%)\end{array}$ & \\
\hline \multicolumn{6}{|l|}{ Proximal } \\
\hline \multirow[t]{2}{*}{$\mathrm{n}=18$} & I & $3(75.0)$ & $1(25.0)$ & - & 4 \\
\hline & $\|$ & $1(7.1)$ & $7(50.0)$ & $6(42.9)$ & 14 \\
\hline \multicolumn{6}{|l|}{ Distal } \\
\hline \multirow[t]{2}{*}{$\mathrm{n}=17$} & I & $9(90.0)$ & $1(10.0)$ & - & 10 \\
\hline & $\|$ & $3(42.8)$ & $2(28.6)$ & $2(28.6)$ & 7 \\
\hline
\end{tabular}

Percentages calculated on the whole number of patients in each level. Grade I, mild injury; grade II, less severe injury. SPA, sports participation absence. 
Table 6 Comparisons of the SPA time between levels depending on the grade

\begin{tabular}{|c|c|c|c|}
\hline \multirow[b]{2}{*}{ Grade } & \multicolumn{2}{|l|}{ Level } & \multirow[b]{2}{*}{ p Value* $(95 \%$ Cl) } \\
\hline & Proximal (SD) & Distal (SD) & \\
\hline I & $32.3(8.5)$ & $25.9(7.3)$ & $0.185 \mathrm{NS}(-3.4$ to 16.2$)$ \\
\hline II & $48.7(13.4)$ & $42.9(13.5)$ & $0.357 \mathrm{NS}(-7.1$ to 18.8$)$ \\
\hline
\end{tabular}

Average (SD). ${ }^{*}$ Independent samples $\mathrm{t}$ test. $95 \% \mathrm{Cl}$, confidence interval of the difference between averages. Grade I, mild injury; grade II, less severe injury. There were no statistically significant differences in the sports participation absence (SPA) time between the two levels in any of the three grades $(p>0.05)$.

then from there to the posterior fascia and are bipennate. These fibres produce a "muscle-within-muscle"appearance at its distal half.

Few series have been published about central tendon injury. ${ }^{8121619}$ Most of these have been retrospective studies or with patients with slowly evolving injuries, with an average duration of 5 months or more. According to Hughes et a $l^{8}$ an injury in the central tendon acts independently producing a shearing phenomenon on the direct head in contrast to what occurs normally in the RF. This hypothesis could explain the longer recovery time associated central tendon injury.

Cross et al, ${ }^{9}$ in a prospective study, compared the rehabilitation interval of eight cases of peripheral injury to seven cases of central tendon injury. When the injury is peripheral, the mean rehabilitation interval is 9.2 days, whereas when the injury is located in the central tendon the mean rehabilitation interval is 26.9 days. This group was made up of professional athletes who received early intervention with gradual rehabilitative therapy. In previous group studies, the subjects studied were high school or collegiate athletes or soldiers and, perhaps, had less rigorous oneone-one initial management after a long delay in consultation.

In our series the mean rehabilitation of the 29 cases of peripheral injury was 15.31 days. This value is similar to that in the series of Cross et al but lower than RF bull's eye injuries. Those injuries were complicated but really well tolerated by patients. The same occurred with the two intermediate vastus muscle injury cases.

Our 14 cases with a negative ultrasound (Peetrons grade 0 ) had a little more SPA time than the average of the three cases with a negative ultrasound in the Cross study. Cross et al $l^{9}$ consider that the lesion was too small to be resolved or the oedema/inflammatory response was delayed until after the "cute" MRI (ie, the MRI was done too early). In ultrasound it is
Table 7 Comparisons of SPA time between grades depending on the diagnostic level

\begin{tabular}{llll}
\hline \multirow{2}{*}{ Level } & \multicolumn{2}{l}{ Grade } & \\
\cline { 2 - 3 } & I (SD) & II (SD) & p Value* $(95 \%$ CI) \\
\hline Proximal & $32.3(8.5)$ & $48.7(13.4)$ & $0.035(-31.6$ to -1.3$)$ \\
Distal & $25.9(7.3)$ & $42.9(13.5)$ & $0.004(-27.7$ to -6.2$)$ \\
\hline
\end{tabular}

Average (SD). *Independent samples t test. $95 \% \mathrm{Cl}$, confidence interval of the difference between averages. Grade I, mild injury; grade II, less severe injury. Comparisons of the sports participation absence (SPA) time between the two grades in each of the two diagnostic levels.

common to delay the exploration 2-3 days to prevent the nondetection of minimum injuries.

Finding an objective prognostic factor by the ultrasound technique has great significance because it allows adaptation of rehabilitation periods and ultimately a decrease in injury recurrence. We have not utilised grade 0 of the Peetrons classification injuries (2002) because it has no ultrasound correlation. $^{9}$

\section{Comparison of SPA between levels (table 4)}

The SPA is significantly higher in proximal injuries (45.1 days) in comparison with distal injuries (32.9 days). This could be related to the largest number of severe injuries occurring in the proximal group (14 of grade II) in relation to the distal group (six of grade II and one of grade III) and a possible delay in consultation as they are more likely to be clinically unnoticed.

In the proximal lesions we can observe the shearing phenomenon described by Hughes et al that might contribute, on one hand, to the majority of the injuries in the proximal level and, on the other, to increase the sensitively of SPA time. This "double effect" could help to understand the proximal injuries as injuries with a worse prognosis than distal ones.

Also, the sartorius may play a role. Frequent exercises in the rehabilitation period, such as easy running and progressive exercises, would enable the sartorius to act as a constrictor of the rectus. This would generate discomfort at the anterior part of the thigh and thus delay the passage from one rehabilitation stage to another.

A possible biomechanical mechanism for proximal injuries of the RF was suggested by Soderberg. ${ }^{20}$ He proposed that by attaching a compliant tissue to a stiff one, the tendon has a very difficult mechanical role in attempting to overcome impedance mismatch. Impedance mismatch occurs when two mechanically

Table 8 Comparison between the injury length depending on the diagnostic level and the SPA time

\begin{tabular}{|c|c|c|c|c|}
\hline \multirow[b]{2}{*}{ SPA time/level } & \multirow[b]{2}{*}{ Length, cm (SD) } & \multicolumn{3}{|c|}{ t Test for the average comparison* } \\
\hline & & $\begin{array}{l}\text { Difference between } \\
\text { averages }\end{array}$ & $95 \% \mathrm{CI}$ & p Value \\
\hline \multicolumn{5}{|l|}{$0-30$ days } \\
\hline Proximal & $1.33(1.12)$ & -1.42 & $(-3.04$ to 0.20$)$ & $0.081 \mathrm{NS}$ \\
\hline Distal & $2.75(1.36)$ & & & \\
\hline \multicolumn{5}{|l|}{$31-45$ days } \\
\hline Proximal & $3.88(0.99)$ & -3.79 & $(-6.04$ to -1.53$)$ & 0.004 \\
\hline Distal & $7.67(2.52)$ & & & \\
\hline \multicolumn{5}{|l|}{$>45$ days } \\
\hline Proximal & $6.00(1.90)$ & 0.50 & $(-3.36$ to 4.36$)$ & $0.763 \mathrm{NS}$ \\
\hline Distal & $5.50(2.12)$ & & & \\
\hline
\end{tabular}


Table 9 Correlation between SPA time (days) and length (cm) depending on the level

\begin{tabular}{lllr}
\hline Level & $\mathbf{n}$ & $\boldsymbol{\rho}$ & $\mathbf{p}$ Value \\
\hline Proximal & 18 & 0.823 & $<0.001$ \\
Distal & 17 & 0.650 & 0.005 \\
Total & 35 & 0.672 & $<0.001$ \\
\hline
\end{tabular}

$\rho$, Pearson correlation coefficient. There is a significant correlation between sports participation absence (SPA) time and the length whether the injury is proximal or distal $(p<0.001, p=0.005)$ and if we study the total representative sample $(p<0.001)$.

different tissues are joined, resulting in strain concentrations in which injury is most likely to occur.

\section{Comparison SPA time between grades (table 5)}

It seems logical that the results confirm that grade II injuries have a greater SPA time (46.3 days, SD 13) than grade I injuries (27.7 days, SD 8) as a result of the increased severity of the lesion. This was confirmed at both proximal and distal levels. There were insufficient grade III lesions in our series to allow us to make comparisons.

There was a statistically significant difference in SPA time between grades I and II $(p<0.001)$, the negative difference in SPA time being what tells us that the grade II SPA time is significantly higher than grade I.

\section{Comparison SPA time between levels depending on the grade of injury (table 6)}

The SPA of injuries in grade I (32.3, SD 8.5) or II (48.7, SD 13.4) at the proximal level are higher than at the distal level (I, 25.9, SD 7.3; II, 42.9, SD 13.5). There were no significant differences in the SPA time between the two levels of diagnosis for any of the three grades that could be attributed to a greater level of significance in the degree of injury.

\section{Comparison SPA time between grades depending on the diagnostic level (table 7)}

We found a significant difference in SPA time at the proximal level between grades I (32.3, SD 8.5) and II (48.7, SD 13.4). In the distal level there was also a significant difference in SPA time observed between grades I (25.9, SD 7.3) and II (42.9, SD 13.5). Logically there were no differences between grades I and III and between grades II and III, due to lack of a sufficient number of cases. These results confirm the significance of the level of injury that influenced the SPA time depending on the grade.

\section{Comparison of injury length with the injury level and the SPA time (table 8)}

There was a direct correlation of injury length to SPA time in proximal lesions. In the group of injuries with shorter SPA time (less than 30 days) we did not find a significant difference in the length of the injury between the proximal and distal location,

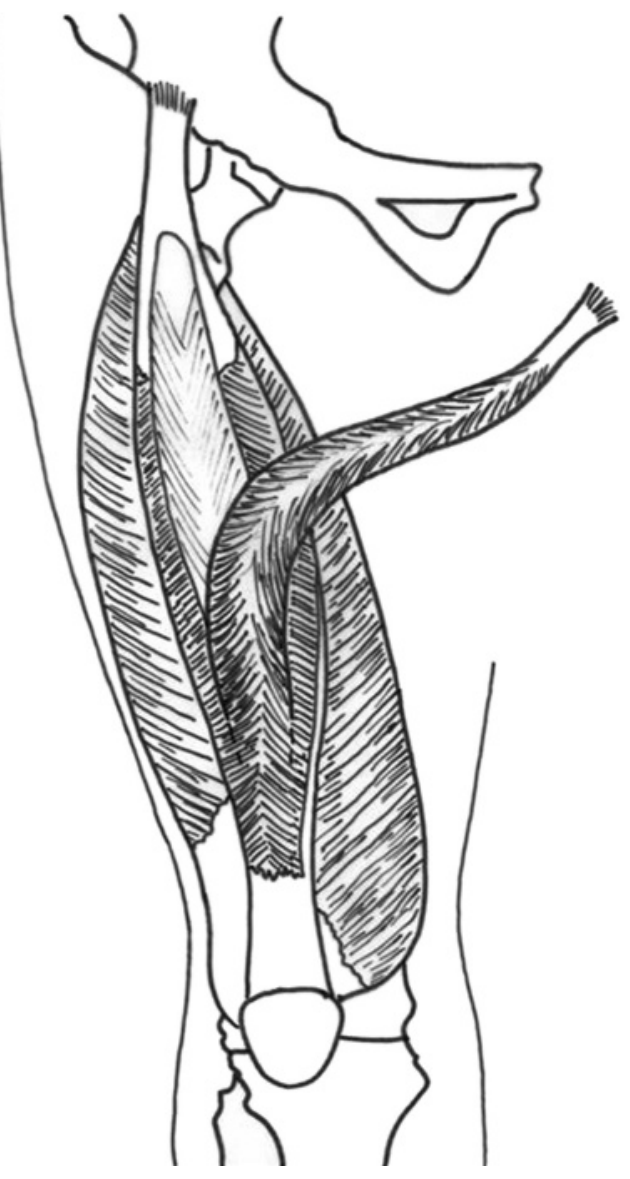

Figure 3 "Muscle-within-muscle".

although we did note a tendency for the proximal level $(1.33 \mathrm{~cm}, \mathrm{SD} 1.12)$ injuries to be shorter than the ones in the distal level $(2.75 \mathrm{~cm}, \mathrm{SD} 1.36)$. We found a significant difference when we compared the group with an SPA time of 31-45 days. In this group, the length is significantly shorter in the proximal level $(3.88 \mathrm{~cm}, \mathrm{SD} 0.99)$ than in the distal one $(7.67 \mathrm{~cm}, \mathrm{SD}$ 2.52). In injuries with an SPA time longer than 45 days, the length of the proximal level injury $(6.0 \mathrm{~cm}, \mathrm{SD} 1.90)$ is higher than the shorter SPA periods and cannot be compared with the distal as there were only two of these cases.

\section{SPA time (days) depending on the injury length $(\mathrm{cm})$ and the} injury level (proximal/distal)

It seems logical that the longest injuries would have longer SPA time. This fact was confirmed both distally and proximally (table 9).

Although the ratios are statistically significant $(p<0.001)$ in the three models, it is noted that the adjusted value of $R^{2}$ is below 0.5 . As a result, our model does not explain more than $50 \%$ of the variability of our data. Therefore, none of the three

Table 10 Regression model (regression coefficients)

\begin{tabular}{|c|c|c|c|c|c|c|}
\hline & \multicolumn{2}{|l|}{ Proximal level } & \multicolumn{2}{|l|}{ Distal level } & \multicolumn{2}{|l|}{ Total } \\
\hline & Coeffiecient $\boldsymbol{\beta}_{\mathrm{i}}$ & p Value & Coefficient $\beta_{\mathrm{i}}$ & p Value & Coefficient $\beta_{\mathrm{i}}$ & p Value \\
\hline (Constant) & $\beta_{0}=45.1$ & $<0.001$ & $\beta_{0}=32.9$ & $<0.001$ & $\beta 0=39.1$ & $<0.001$ \\
\hline Length $(\mathrm{cm})$ & $\beta_{1}=5.3$ & $<0.001$ & $\beta_{1}=3.4$ & 0.005 & $\beta 1=4.2$ & $<0.001$ \\
\hline Model & \multicolumn{2}{|c|}{ SPA $=45.1+5.3($ long -4.0$)$} & \multicolumn{2}{|c|}{ SPA $=32.9+3.4($ long -3.9$)$} & \multicolumn{2}{|c|}{$\mathrm{SPA}=39.1+4.2($ long -4.0$)$} \\
\hline $\mathrm{R}^{2}$ & \multicolumn{2}{|l|}{0.667} & \multicolumn{2}{|l|}{0.422} & \multicolumn{2}{|l|}{0.442} \\
\hline
\end{tabular}

$\beta_{\mathrm{i}}$, Lineal regression model coefficients; $\mathrm{R}^{2}$, fit goodness coefficient. SPA, sports participation absence. 


\section{What this study adds}

RF central tendon injury at the proximal level is associated with a greater SPA time than at the distal level. Ultrasound is helpful in predicting the prognosis for acute central tendon RF injuries.

\section{What is already known on this topic}

$\mathrm{RF}$ injuries are one of the most frequent injuries in the thigh. Within the lesions of the rectus, those affecting the central tendon have longer SPA time.

models appear to be good predictors of the SPA time dependent solely on the injury length. We do not agree with this adjustment because other variables affect the SPA time such as the grade of injury. This is substantiated by the fact that injuries involving the RF central tendon are known to evolve erratically. ${ }^{17}$

Therefore, the injury length is correlated with SPA time, whether the injury is located proximal or distal. Although injury length itself was not sufficient to predict the SPA time as other variables need to be taken into account.

\section{CONCLUSION}

RF central tendon injury at the proximal level is associated with a greater SPA time than at the distal level. Patients with a grade II injury have an SPA time longer than those with a grade I injury whether the injury is located proximal or distal. Greater injury length corresponds to longer SPA time, although we cannot say that the injury length by itself is enough to predict the SPA time of an RF central tendon injury.

Acknowledgements: The authors would like to thank Dr David Bong (Vancouver Clinic, Vancouver Washington) for advice on the translation.

Competing interests: None.
Ethics approval: Ethics approval was obtained from the Consell Catala de l'esport. Patient consent: Obtained.

\section{REFERENCES}

1. Soterios G, Zehava Sadka R, Schweitzer M, et al. Normal anatomy and strains of the deep musculotendinous junction of the proximal rectus femoris: MRI features. Am J Roentgenol 2008;190:W182-6.

2. Waldén $\mathbf{M}$, Hägglund $\mathbf{M}$, Ekstrand J. UEFA Champions League study: a prospective study of injuries in professional football during the 2001-2002 season. Br J Sports Med 2005;39:542-6.

3. Hägglund $\mathbf{M}$, Waldén $\mathbf{M}$, Ekstrand J, et al. Methods for epidemiological study of injuries to professional football players: developing the UEFA model. Br J Sports Med 2005;39:340-6

4. Alonso M, Uribe I. DOMS: dolor muscular de aparición retardada. Apunts Medicina de l'esport 2001;36:5-13.

5. Hascelik Z, Guner R, Ülkar B, et al. Comprehensive isokinetic knee measurements and quadriceps tendón evaluations in footballers for assessing functional performance. Br J Sports Med 2003;37:507-10.

6. Gibbon WW. Diagnostic ultrasound in sports medicine. Br J Sport Med 1998:32:3

7. Walton JM, Roberts N, Whitehouse GH. Measurement of the quadriceps femoris using magnetic resonance and ultrasound imaging. Br J Sports Med 1997;31:59-64.

8. Hughes C, Hasselman C, Best $T$, et al. Incomplete, intrasubstance strain injuries of the rectus femoris muscle. Am J Sports Med 1995;3:500-6.

9. Cross TM, Gibbs N, Houang $M$, et al. Acute quadriceps muscle strains: magnetic resonance imaging features and prognosis. Am J Sports Med 2004;32:710-19.

10. Bordalo-Rodrigues $\mathbf{M}$, Rosenberg ZS. MR imaging of the proximal rectus femoris musculotendinous unit. Magn Reson Imaging Clin N Am 2005:13:717-25.

11. Peetrons P. Ultrasound of muscles. Eur Radiol 2002;12:35-43.

12. Bianchi S, Martinoli C, Waser N, et al. Central aponeurosis tears of the rectus femoris: sonographic findings. Skeletal Radiol 2002;31:581-6.

13. Ekstrand J, Walden M, Hägglund M. A congested football calendar and the wellbeing of players: correlation between match exposure of European footballers before the World Cup 2002 and their injuries and performances during that World Cup. Br J Sports Med 2004;38:493-7.

14. Orchard J, Best T, Verrall G. Return to play follow muscular strains. Clin J Sport Med 2005;6:436-41.

15. Guerrero M, Guiu-Comadevall M, Cadefau J, et al. Fast and slow myosins as markers of muscle injury. Br J Sports Med 2008;42:581-4.

16. Balius R, Estruch $A$, Guerrero $M$, et al. Valor diagnóstico de las miosinas séricas en las lesiones musculares. Apunts Medicina de l'esport 2005:146:25-30.

17. Hasselman C, Best T, Hugues $\mathrm{C}$, et al. An explanation for various rectus femoris strain injuries using previously undescribed muscle architecture. Am J Sports Med 1995;23:493-9.

18. Burns B, Sproule J, Smyth H. Acute compartment syndrome of the anterior thigh following quadriceps strain in a footballer. Br J Sports Med 2004;38:218-20.

19. Rask MR. Lattig GJ. Traumatic fibrosis of the rectus femoris muscle. Report of five cases and treatment. JAMA 1972;221:268-9.

20. Soderberg G. Muscle mechanics and pathomechanics. Their clinical relevance. Physical Ther 1983;3:216-20. 